\title{
Surgical Techniques in Moyamoya Vasculopathy. Tricks of the Trade by Peter Vajkoczy (2019) 206 pp, 471 illustrations Hardback ISBN: 9783131450616 (eBook, elSBN 978-3-13-147081-2) Thieme Publishers New York/Stuttgart
}

\author{
R. Michael Scott ${ }^{1}$ (I) \\ Received: 18 April 2020 / Accepted: 21 April 2020 / Published online: 7 May 2020 \\ (C) Springer-Verlag GmbH Austria, part of Springer Nature 2020
}

This text is a compendium of neurosurgical approaches to the management of moyamoya vasculopathy. It consists of 23 multiauthored chapters that cover surgical considerations ranging from anesthetic management and the more commonly used procedures, such as cerebral bypass and indirect revascularizations, to the more rarely used and more "exotic" ones, such as omental transposition and occipital artery to middle cerebral artery anastomosis. Virtually all of the chapters are co-authored by senior figures in the field of vascular neurosurgery.

The editor, and co-author of 5 of the book's chapters, Peter Vajkoczy, has taken an interesting approach to the topic: he has asked each set of authors to approach their subjects from the perspective of a "SWOT" analysis - giving their procedure's strengths, weaknesses, opportunities, and threats (presumably meaning threats to the approach's continued usefulness and viability). Each set of authors must have struggled to make a statement or two that was relevant to their topic's "opportunities" and "threats" - but this editorial ploy does lead to a similarity of chapter organization that many readers will welcome. Sections in each chapter are also allocated to rescue strategies and tips and pearls, which also provide some very helpful pointers for neurosurgeons of all degrees of experience as they manage these often difficult patients. Unfortunately, Thieme has cluttered the chapter index of the book by independently listing each of these repetitive subheadings, and a simpler chapter listing would have sufficed given the similar structure of each one.

R. Michael Scott

michael.scott@childrens.harvard.edu

1 Harvard Medical School, Boston Children's Hospital, Boston, MA 02115, USA
The book has the advantages and disadvantages of any multi-authored text. The quality of the illustrations in the print version is quite uneven. They are also duplicative and sometimes too numerous in each chapter to clearly convey the points the authors are trying to make. The reddish cast of many of the operative photos in the print edition makes differentiation of anatomic structures difficult. The eBook is a significant advance in this respect, with the color quality and definition of the images much improved in this format, with magnification easily done by the reader when required. Personal prejudices of the authors are presented as dogma, as for example, the statement that intravenous anesthesia is preferable to inhalational agents in moyamoya patients and that arterial lines for monitoring blood pressure might be "considered," when many consider them mandatory. "Do not use staples to apply drapes," states one authority in the text, and hopefully, readers recognize that there are perhaps opposite and equally valid opinions on some of these matters. Nevertheless, even this seasoned vascular pediatric neurosurgeon learned some new technical tricks from the authors of this text. I was, however, sorry to see that some of my favorite procedures, including pial synangiosis, and various rescue procedures for anterior cerebral artery territory ischemia, such as modified dural inversions and galeal and periosteal inversion, were given short shrift or not mentioned at all.

This text certainly fulfills the objective of its editor, “... to create an instructive manual for neurosurgeons with a step-bystep guide to the surgical techniques" for moyamoya vasculopathy. Neurosurgeons at all levels of expertise will benefit from its perusal.

Publisher's note Springer Nature remains neutral with regard to jurisdictional claims in published maps and institutional affiliations. 